\title{
LA IGNORANCIA DEL PODER. ACERCA DE LA VIOLENCIA Y EL MAL EN LA FILOSOFÍA POLITICA DE HANNAH ARENDT
}

José Carlos Loyola

Pontificia Universidad Católica del Perú

A partir de una aproximación al ensayo Sobre la violencia, intentaremos comprender la relación que existe entre la violencia y el mal en la filosofía de Hannah Arendt. El artículo partirá ubicando el tratamiento crítico arendtiano de la noción kantiana del mal radical en Los orígenes del totalitarismo, y el vuelco que da su pensamiento en el tratamiento del mal al formular en Eichmann en Jerusalén la posibilidad de que las acciones humanas puedan tener motivaciones banales. Según nuestro punto de vista, es posible establecer una relación de continuidad entre esta banalidad del mal con la idea de mal radical, en tanto ambas concepciones del mal se refieren a la anulación efectiva del carácter espontáneo de las acciones humanas. Asimismo, sugeriremos que dicho tratamiento del problema del mal arendtiano puede entenderse en estrecha relación con sus investigaciones sobre el ejercicio de la violencia sistemática en los regímenes totalitaristas y sus tesis sobre la naturaleza del poder en los regímenes políticos. La ignorancia del poder designará, así, tanto un equívoco teórico sobre la naturaleza del poder, como el modo efectivo en el que el mal se encuentra presente en regímenes políticos que apuntan a dominar, mediante la violencia, las acciones de los hombres.

Palabras clave:

mal, violencia política, poder, Arendt, Kant 


\section{Introducción}

¿Qué relación guarda, según Hannah Arendt, el mal con la violencia? ¿Es acaso la violencia equiparable con el mal y, en particular, con el mal radical que motivó gran parte de sus reflexiones filosóficas? A pesar de ser ambos temas recurrentes de su pensamiento, no resulta del todo sencillo establecer una relación clara entre ambos. Innegablemente, Los orígenes del totalitarismo se ha convertido en una obra paradigmática de la comprensión filosófico-política de los alcances de la violencia en la historia de la humanidad; sin embargo, y tal como Richard Bernstein ha señalado acertadamente, no debe perderse de vista que con esta obra se inicia, además, una reflexión filosófica que discute abiertamente con una concepción tradicional del mal y, específicamente, con la noción de mal radical kantiano'.

Tal como buscaremos demostrar, es posible establecer, a partir de la interesante reflexión de Richard Bernstein sobre el mal radical en la obra de Hannah Arendt, un vínculo entre el problema de mal y la violencia en su obra filosófica. Ello sin embargo nos presenta la exigencia de conocer el desarrollo. Como es bien sabido, la aparición de esta discusión con respecto a la naturaleza del mal radical en la filosofía de Arendt se ubica en el contexto político del totalitarismo nazi y tendrá su desarrollo posterior en la figura de Eichmann, personaje a través del cual Arendt presentará una nueva manera de entender el mal radical como mal banal. Si bien se tratará de una concepción del mal que no resulta ser incompatible con la anterior, esta nos dejará frente a nuevas perspectivas del tema. Con su reporte acerca del juicio de Eichmann en Jerusalén, Arendt nos sugiere la comprensión de las motivaciones malignas de los individuos como motivaciones superfluas, una nueva comprensión del mal como fenómeno en el que las motivaciones mismas de las acciones humanas resultan ser banales.

\footnotetext{
' Cf. Bernstein, Richard, El mal radical: una indagación filosófica, Buenos Aires: Lilmod, 2005, p. 307. En efecto, como veremos más adelante, mientras que Kant niega que la radicalidad del mal atente contra el irrestricto carácter moral de los seres humanos, es decir, contra la espontánea determinación de las motivaciones de sus actos, Arendt planteará una concepción de mal radical como fenómeno en el que los seres humanos pierden de facto toda espontaneidad.
} 
No brindaremos en esta ocasión un análisis in extenso de la concepción arendtiana del mal y su desarrollo. La intención de nuestro trabajo es sugerir que, para comprender su crítica a la concepción tradicional del mal, es necesario atender a la noción de violencia propuesta por Arendt y la relación que esta guarda tanto con su concepción acerca del mal como con su análisis de los regímenes totalitaristas. Para ello, atenderemos a su famoso ensayo Sobre la violencia (1969), en el que muestra, con una claridad propia de su etapa de madurez filosófica, que la equívoca asociación entre violencia y política puede identificarse como el trasfondo ideológico del surgimiento de regímenes políticos como el nazi. Según su punto de vista, se hace necesario criticar la perpetuación de una hipótesis pseudo-científica acerca de la política que vincula la violencia con el poder. Atendiendo a que, al definir la banalidad del mal de Eichmann, Arendt se refiere a una suerte de la falta de reflexividad o incapacidad para pensar, sugeriremos entender a la perpetuación de esta mala comprensión del poder político como una ignorancia del poder, ignorancia que puede entenderse en dos sentidos, y que nos permitiría comprender la estrecha relación que se establece en su filosofía entre mal y violencia.

En primer lugar, por ignorancia del poder entendemos la asociación que a nivel teórico se ha establecido entre el uso de la violencia y la política en la historia de la filosofía política. Esta relación, en opinión de Arendt, ha postergado el reconocimiento de la espontaneidad de la acción como rasgo fundamental de las acciones humanas y como fin mismo de la política. "La acción política", piensa Arendt, "[...] como cualquier otro tipo de acción es siempre esencialmente el comienzo de algo nuevo" 2 . Tal como buscará demostrar en su ensayo Sobre la violencia, la acción política está emparentada, en ese sentido, con el poder entendido como la posibilidad de concertar y sostener acciones. En contraposición, la violencia anula siempre la posibilidad de nuevas acciones. Así lo muestra el análisis de distintas teorías políticas que Arendt realiza en este texto; se trata de una distinción básica de la naturaleza del poder que no ha sido reconocida, dando lugar así a teorías políticas pseudo-científicas que justifican regímenes políticos violentistas como los totalitarios.

\footnotetext{
${ }^{2}$ Arendt, Hannah, "Comprensión y política”, en: Arendt, Hannah, De la historia a la acción, traducción de Fina Birulés, Barcelona: Paidós, 1995, p. 43.
} 
En segundo lugar, entendemos dicha ignorancia del poder como un ejercicio de la política presente en la historia de la humanidad y en el que se ha tentado anular de facto el despliegue de la espontaneidad de las acciones humanas. Según Arendt, una equívoca relación entre el poder y la violencia se manifestaría en los regímenes políticos y puede ser pensada como una clave para comprender el advenimiento de una nueva forma de mal. El totalitarismo habría apuntado a tener un dominio total de los individuos mediante la violencia y habría inaugurado con ello, según Arendt, una forma de mal radical que es indisociable tanto de la irreflexividad propia de nuestra comprensión común sobre la política como de la postergación efectiva de la espontaneidad de las acciones humanas.

\section{§ 1. La aparición del mal radical}

Abocada desde sus primeros trabajos a un análisis del fenómeno del totalitarismo a comienzos de siglo, Arendt busca elaborar una obra filosófica que muestre la profunda necesidad de repensar la naturaleza de los asuntos prácticos humanos y que, por ende, apunte a desentrañar y evaluar nuestros más habituales prejuicios sobre lo que es la política ${ }^{3}$. Entre estos, nuestros prejuicios acerca de la relación que tiene la política con la violencia son casi tan problemáticos como paradigmáticos. Los orígenes del totalitarismo, su primera obra publicada de filosofía política, nos muestra cómo la humanidad ha sido testigo del advenimiento de un orden político como el nazi que, teniendo como objetivo la dominación total de los individuos, amplía el uso de la violencia al punto de aniquilar por completo la individualidad misma de los seres humanos ${ }^{4}$. Este aniquilamiento, según su punto de vista, tendría tres momentos:

\footnotetext{
${ }^{3}$ De hecho, en los últimos años de su producción filosófica, Arendt habría pensado escribir una obra en la que estaría resumida su concepción -o mejor dicho, su elaborada redefinición- de qué es la política. Uno de los manuscritos conservados de ese trabajo inconcluso, que lleva justamente por título tentativo "Introducción a la política", se inicia con la siguiente reflexión: "En nuestro tiempo, si se quiere hablar de política, debe empezarse por los prejuicios que todos nosotros, si no somos políticos de profesión, albergamos hacia ella" (Arendt, Hannah, ¿Qué es la política?, traducción de Fina Birulés, Barcelona: Paidós, 1997, p. 49).

${ }^{4}$ Cf. Arendt, Hannah, Los orígenes del totalitarismo, Madrid: Alianza Editorial, 1982, 3v., vol. 3, pp. 587-588. En adelante, OT.
} 
I. La muerte de la persona jurídica en el individuo: una destrucción de la dimensión legal de los individuos que se establece como requisito para la dominación total ${ }^{5}$. Con ello, Arendt se refiere al proceso mediante el cual se despojó a los judíos de todos sus derechos civiles, incluso desde antes de ser llevados a los campos de concentración, con el objetivo inmediato de permitir tanto la selección arbitraria como el anonimato en el exterminio de los individuos.

2. La muerte de la persona moral que hay en el individuo: un olvido organizado o un rechazo sistemático al reconocimiento de las personas que son aniquiladas, tanto a nivel público como privado 6 . Arendt afirma que se trata del momento en el que "se ha corrompido toda solidaridad humana”, pues “[...] el mundo occidental, incluso en sus más negros períodos, siempre otorgó al enemigo muerto el derecho de ser recordado como un reconocimiento evidente del hecho de que todos somos hombres (y solamente hombres)"7.

3. La muerte de la individualidad del individuo: una anulación de su corporeidad que tiene la peculiaridad de anular además su singularidad. Arendt ubica esta fase del aniquilamiento humano en los campos de concentración de las SS, una experiencia en la que se elimina la identidad del individuo al punto de que "[...] los seres humanos pueden ser transformados en especímenes del animal humano"8.

El advenimiento de esta última fase supone una novedad crucial en los regímenes políticos y su uso de la violencia, fase que coincide con el planteamiento arendtiano de un mal radical. En efecto, Arendt concluye sus reflexiones sobre el totalitarismo señalando la aparición entre los hombres de un mal radical que, aunque resulta ser indiscernible en términos absolutos, tiene una peculiaridad: ha emergido en relación con un sistema político en el que los hombres se tornan superfluos 9 . Por tornar superfluos a los hombres, Arendt entiende la anulación de una característica fundamental de los individuos, a saber, la espontaneidad de sus acciones a través de la violencia ejercida. La

\footnotetext{
${ }^{5}$ Cf. OT, vol. 3, p. 583.

${ }^{6}$ Cf. ibid., p. 584.

${ }^{7}$ lbid.

${ }^{8}$ lbid., p. 588.

${ }^{9}$ Cf. ibid., p. 593.
} 
poca oposición al aniquilamiento masivo, incluso la extraña incidencia de suicidios en los campos de concentración ${ }^{10}$, son solo algunos de los hechos que dejan a Arendt con la certeza de que el régimen político totalitario instaurado por el hombre concibe la absoluta necesidad de establecer una sociedad de "moribundos" en la que se hace posible la dominación total. Según su punto de vista, destruir la individualidad de los seres humanos es, innegablemente, dominarlos en un sentido absoluto, pues es destruir "[...] el poder del hombre para comenzar algo nuevo, a partir de sus propios recursos, algo que no puede ser explicado sobre la base de reacciones al medio ambiente y a los acontecimientos"'.

Tal como Bernstein ha afirmado acertadamente, con estas reflexiones se plantea en la obra de Arendt una concepción del mal que, más allá de su crítica al régimen político totalitario, cuestiona una larga tradición filosófica moral que ha ubicado el problema del mal en el ámbito de las motivaciones del individuo ${ }^{2}$. En particular, Arendt reta al pensamiento moral kantiano al afirmar la posibilidad de que el mal radical pueda existir en el mundo de los hombres. Arendt critica el modelo kantiano del mal radical en tanto que este afirma que la voluntad humana tiene la peculiaridad de no poder ser determinada por ningún motivo impulsor que el hombre no admita como máxima de su acción ${ }^{13}$. Arendt discute abiertamente la tesis kantiana de que no sea posible que el motivo mismo de la acción de un individuo se sostenga sobre la absoluta espontaneidad de su voluntad. A diferencia de Kant, quien niega que la radicalidad del mal atente contra la espontaneidad misma de la elección de la máxima de los actos (la aptitud de la llamada Willkür kantiana ${ }^{14}$ ), Arendt plantea una concepción de mal radical como fenómeno en el que los seres humanos pierden de facto toda espontaneidad. Así, la superfluidad de los hombres atribuida al mal radical no deberá ni podrá ser entendida en términos kantianos. No se trata de la mera perversión de una voluntad humana que, a pesar de todo, puede seguir gobernando espontáneamente sus actos, se trata de la aparición en un mundo

${ }^{10}$ Cf. ibid., p. 588.

"lbid.

${ }^{12}$ Cf. Bernstein, Richard, op. cit., p. 307.

${ }^{13}$ Cf. Kant, Immanuel, La religión dentro de los límites de la mera razón, Madrid: Alianza Editorial, 2002, p. 41. 
humano de "[...] reflejos condicionados, de marionetas"15, en suma, de una efectiva destrucción sistemática de la libertad humana en la acción.

\section{§ 2. El desafío de la comprensión de las motivaciones del mal radical: la banalidad del mal}

Es innegable para Arendt que, sin el desarrollo de las etapas finales del totalitarismo, a saber, las etapas más cruentas del genocidio nazi, "[...] no podríamos haber conocido jamás la naturaleza verdaderamente radical del mal" ${ }^{\prime \prime}$. Con el triple asesinato de la persona, se anula toda espontaneidad de las acciones humanas; con ello, Arendt ataca una visión kantiana del mal radical que concibe que el mal pueda llegar a ser entendido únicamente como una suerte de perversión de las motivaciones del agente.

El problema de las motivaciones del mal radical no es para Arendt, sin embargo, un asunto que pueda ser fácilmente zanjado por el análisis filosófico-político. De hecho, este deriva en una suerte de análisis del estado en que quedan las motivaciones humanas en esta perpetración del mal radical. ¿Qué deberíamos decir de las motivaciones humanas en un mundo donde los hombres se han tornado superfluos? La respuesta a esta interrogante en Los orígenes del totalitarismo parece ser tan enigmática como estimulante: este mal radical constituye un desafío abierto para la humanidad, pues las motivaciones mismas de este se escapan, al igual que sus actos, de toda posibilidad de comprensión humana ${ }^{17}$.

El reporte acerca del juicio de Eichmann en Jerusalén corresponde, sin duda, a un denodado esfuerzo por adentrarse aún más en este problema. Atendiendo a la necesidad de comprender la culpabilidad detrás de estos crímenes del

\footnotetext{
${ }^{15}$ Cf. OT, vol. 3, p. 590.

${ }^{16}$ OT, vol. I, pp. VIII-IX.

${ }^{17}$ Cf. ibid. Esta tesis será precisada en un artículo de 1957 que lleva por título "Comprensión y política". Es imposible comprender en términos absolutos el mal radical. De hecho, la comprensión en sí misma, piensa Arendt, "[...] es un proceso que nunca da resultados inequívocos"; se trata, en definitiva, de "una actividad sin fin, siempre diversa y mutable" y que tiene la peculiaridad de ser aquella actividad humana mediante la que "aceptamos la realidad, nos reconciliamos con ella [...]” (Arendt, Hannah, “Comprensión y política”, p. 29).
} 
totalitarismo que, según su punto de vista, van más allá de toda legalidad posible y escapan a todo castigo concebible, Arendt evalúa su primer acercamiento a la profundidad de las motivaciones malignas de los individuos. La polémica abierta con Gershom Scholem, acerca del término "banalidad del mal" nos muestra claramente la tesis que comenzará a barajar al respecto: "En efecto, ahora opino que el mal nunca es 'radical', que sólo es extremo y que no posee profundidad ni dimensiones demoníacas. Puede crecer anormalmentey asolar el planeta porque se esparce como un hongo por la superficie. Es 'desafiante para el pensamiento' como dije, porque el pensamiento trata de llegar a algo profundo, de ir hasta la raíz y cuando se ocupa del mal, se frustra, porque no encuentra nada. Esa es la 'banalidad'”|'.

Tal como Arendt afirma, no debe entenderse mal radical como un mal cuyas motivaciones sean profundas, o tal vez, demoníacas. La incomprensión del mal de Eichmann, uno de los principales artífices del aniquilamiento masivo del régimen nazi, no debe, según esta apreciación, ser confundida por tratarse en el fondo de un mal de orígenes insondables en las motivaciones de dicho personaje; más aún, "salvo por una extraordinaria aplicación en pos de progresar personalmente" afirma Arendt, es posible concebir que el mal de Eichmann "no tenía ningún otro motivo"|9. A pesar de la magnitud de los actos perpetrados, el mal radical planteado en Los orígenes del totalitarismo podría poseer, tal como Arendt misma afirma, motivaciones banales.

No es sencillo comprender a qué se refiere exactamente Arendt por dicha banalidad y porqué ella se opone en su pensamiento a profundidad. Creemos que la principal aclaración explícita de lo que significa la expresión la encontramos en su introducción a La vida del espíritu. En ella, Arendt retoma el motivo del análisis de la culpabilidad de Eichmann señalando que éste no tenía motivaciones malignas, ni tampoco era la estupidez la que determinaba sus actos, sino más bien una incapacidad para pensar ${ }^{20}$. Tal como Richard

\footnotetext{
${ }^{18}$ Arendt, Hannahy Gershom Scholem, "Eichmann in Jerusalem: An Exchange of Letters between Gershom Scholem and Hannah Arendt", en: Arendt, Hannah, The Jew as Pariah: Jewish Identity and Politics in the Modern Age, Nueva York: Grove Press, reeditado por Ron Feldman, 1978, p. 245 (citado de Bernstein, Richard, op. cit., p. 304).

${ }^{19}$ Arendt, Hannah, Eichmann en Jerusalén: un reporte sobre la banalidad del mal, Barcelona: Lumen, 1999, p. 287.

${ }^{20}$ Cf. Arendt, Hannah, La vida del espíritu, Barcelona: Paidós, 2002, p. 30.
} 
Bernstein ha señalado acertadamente, la intención de entender esta falta de reflexividad detrás de la banalidad del mal corresponde al desarrollo del análisis arendtiano de la acción humana, análisis en el cual se añade a la característica básica de la espontaneidad otras más, tales como natalidad, libertad, pluralidad y, finalmente, el juicio o capacidad de juzgar como rasgo indisociable de la acción ${ }^{21}$. Igualmente, Bernstein ha hecho esfuerzos por mostrar cómo, si bien la banalidad del mal resulta ser una nueva concepción del mal mismo, esta no es una concepción que resulte ser necesariamente incompatible con la anterior consideración del mal radical en Los orígenes del totalitarismo, pues ambas coinciden en afirmar la posibilidad de que suceda aquello que Kant no contemplaba, a saber, arrancar la espontaneidad del hombre ${ }^{22}$.

No obstante la pertinencia de los apuntes de Bernstein creemos que, sin embargo, poco se dice en su trabajo acerca del lugar que adquieren en la filosofía de Arendt los análisis políticos de Los orígenes del totalitarismo a partir de esta nueva caracterización de las motivaciones humanas del mal. La denuncia de la banalidad de las motivaciones de Eichmann constituye una tesis que, aunque compleja y polémica, no cuestiona en absoluto la capacidad destructiva ni la capacidad expansiva del mal perpetrado históricamente por el régimen político nazi: tal como la propia Arendt sugiere, la banalidad del mal no debe subestimarse, pues puede expandirse tal como un hongo se expande en la superficie. En ese sentido, nuestro artículo pretende esbozar una hipótesis respecto a las reflexiones arendtianas de las motivaciones banales del mal que nos permita vislumbrar el vínculo que estas tienen con el análisis político del totalitarismo.

En lo que sigue, trataremos de demostrar cómo la definición de la banalidad como irreflexibilidad o incapacidad para pensar nos sugiere que, según Arendt, en la historia del advenimiento del totalitarismo ha operado una suerte de ignorancia acerca de lo que es el poder político en sí mismo. No se tratará de una ignorancia pasiva, sin efectos concretos identificables: ella es una ignorancia con la cual (a) se posterga, de modo efectivo, el reconocimiento de la

\footnotetext{
${ }^{21}$ Cf. Bernstein, Richard, op. cit., p. 296.

${ }^{22}$ Cf. Bernstein, Richard, "¿Cambió Hannah Arendt de opinión? Del mal radical a la banalidad del mal”, en: Birulés, Fina (comp.), Hannah Arendt: el orgullo del pensar, Barcelona: Gedisa, 2000, pp. 235-257.
} 
espontaneidad característica de las acciones de los seres humanos y sobre la cual (b) fue posible anular la espontaneidad de las acciones humanas mediante un régimen político que aspiraba a la dominación total.

Para demostrar esta tesis, nos remitiremos a su ensayo Sobre la violencia (1969), en el cual Arendt señala que, contrariamente a lo que se ha pensado, la violencia no puede generar poder político por la racionalidad instrumental -de medios a fines- que es inherente a esta. En contraposición a posturas como las de Weber ${ }^{23}$, que estudian el carácter instrumental de las acciones humanas, la lectura de Arendt no identifica el poder con la coacción violenta, pues el poder corresponde a la capacidad humana de realizar acciones concertadas, cuyos fines son, en sí mismos, imprevisibles. Así, y teniendo reparos en no identificar al mal con la violencia, mostraremos cómo para Arendt el pensamiento tradicional ha caído siempre en el vicio irreflexivo de concebir el uso de la violencia como la aparición de un mal "necesario" de la política: un medio precario pero eficaz que nos permite aspirar a fines instrumentalmente predispuestos (principalmente, a la efectiva cohesión política de las comunidades humanas). De ello a la justificación del uso deliberado de la violencia extrema hay mucho menos que un paso; se trata de una característica esencial de regímenes políticos en los que se atenta flagrantemente contra la fundamental espontaneidad de las acciones humanas y en los que, consecuentemente, los seres humanos pueden tornarse superfluos o, las motivaciones de sus actos, banales.

\section{§ 3. Violencia y política}

Arendt es optimista al afirmar que los seres humanos somos capaces de derrotar al mal como mal político. Tal como señalará en Comprensión y política (1957), esta derrota supondrá que, en nuestro intento por comprender el totalitarismo, la violencia deje de tener un papel preponderante en nuestra concepción de poder. Esto se debe a una razón nada sencilla: "[...] la violencia, a diferencia del poder, es muda; comienza allí donde acaba el discurso [...]”24.

${ }^{23}$ Cf. Weber, Max, Economía y sociedad, México D.F.: FCE, 1974, p. 49.

\footnotetext{
${ }^{24}$ Arendt, Hannah, "Comprensión y política”, p. 30.
} 
Es en el ensayo de madurez Sobre la violencia $(1969)^{25}$ donde Arendt desarrollará esta diferencia entre lo que es el poder y la violencia. La intención fundamental de este ensayo será mostrar que la violencia, dada su racionalidad instrumental, resulta ser diametralmente distinta al poder, el cual será definido como la capacidad humana de concertar, mediante el discurso, las acciones humanas ${ }^{26}$. Para poder explicar esta distinción pasaremos, en este capítulo, a explicar con detenimiento el análisis arendtiano de la naturaleza instrumental de la violencia y cómo esta ha permitido una perversión de la política en la que ha sido posible confundirla con el poder.

Según Arendt, “[...] la verdadera sustancia de la acción violenta es regida por la categoría medios-fin" ${ }^{27}$. Dada su racionalidad instrumental, la violencia entra en el marco de las acciones del tipo productivo; ella solo señala medios para conseguir fines determinados. Ahora bien, este carácter instrumental de la violencia es peculiar, pues tiene el efecto ilusorio de hacernos pensar que se trata de acciones que hacen de antemano alcanzables los fines generales de las acciones humanas. Tal como había afirmado en La condición humana: “[...] si no hubiera nada más en juego que el uso de la acción como medio para alcanzar un fin, está claro que el mismo fin podría alcanzarse mucho más fácilmente en muda violencia, de manera que la acción no parece un sustituto muy eficaz de la violencia" 28 .

A partir de la racionalidad instrumental de la violencia podemos desvirtuar la naturaleza misma de la acción humana en tanto que podemos pensar que esta última puede ser reemplazada por la simple obtención violenta de fines predispuestos. Esta tesis resulta ser decisiva para comprender la relación perniciosa que ha tenido, durante siglos, la violencia con la política. Con ello se describe, según Arendt, no sólo la naturaleza de la violencia en sí misma, sino además una hipótesis tradicional de la filosofía política.

A lo largo de los siglos de historia plagados de políticas que apelan a la violencia como instrumento de poder, parece no haberse querido discutir el

\footnotetext{
${ }^{25}$ Arendt, Hannah, Sobre la violencia, Madrid: Alianza Editorial, 2005. En adelante, SV.

${ }^{26}$ Cf. ibid., p. 70ss.

${ }^{27}$ Ibid., p. 10.

${ }^{28}$ Arendt, Hannah, La condición humana, Barcelona: Paidós, 2002, p. 203.
} 
presupuesto de que, en política, la violencia es el modo común mediante el cual se puede lograr el objetivo básico de cohesionar a las comunidades humanas. Así, en Sobre la violencia, Arendt procede a criticar la vigencia de un realismo político que de facto ha permanecido incuestionable tanto en gobiernos como en los movimientos políticos. Tanto las tesis hobbesianas y weberianas, que proponen a la violencia como el modo mediante el cual se sostienen los acuerdos políticos humanos, así como las tesis fundamentales de la teoría político-militar de Clausewitz sobre la guerra tienen, para Arendt, una vigencia palpable en el escenario político internacional y también en las diversas propuestas políticas de su época, en especial aquellas marcadas por una inspiración marxista, en cualquiera de sus vertientes ${ }^{29}$.

La tesis de que la violencia es el elemento cohesionador básico de las comunidades humanas (o en todo caso, el motor de las transformaciones políticas) resulta ser, para Arendt, el efecto hipnótico de pseudo-teorías políticas que desvirtúan la naturaleza misma de las acciones humanas. Siguiendo en la línea de su tesis inicial acerca de la fundamental espontaneidad de las acciones humanas, Arendt afirmará que estas últimas son "[...] hechos que interrumpen el proceso rutinario y los procedimientos rutinarios" ${ }^{30}$. Suponen siempre un "nuevo comienzo" por el hecho de que nunca pueden ser absolutamente predecibles. Así, nuestras hipótesis anticipatorias sobre los fines generales de las acciones humanas no son más que "[...] proyecciones de procesos y procedimientos automáticos presentes que sería probable que sucedieran si los hombres no actuaran y si no ocurriera nada inesperado" ${ }^{31}$. No es posible establecer a ciencia cierta los fines mismos de todas las acciones humanas, pues cada acción, dice Arendt, "[...] para bien y para mal [...] destruye toda la trama en cuyo marco se encuentra la predicción y donde encuentra su prueba" ${ }^{32}$. Al pensar las acciones violentas como aquel elemento primordial desde el cual aseguramos la vigencia a futuro de determinados acuerdos, se

\footnotetext{
${ }^{29}$ Esto demuestra, para Arendt, la mala comprensión que se tiene del pensamiento de Marx. Según su punto de vista, Marx afirma que, si bien la violencia se ha hecho patente en la transformación efectiva de las sociedades modernas, lo decisivo en cuanto a los asuntos prácticos humanos está ubicado en el "metabolismo con la naturaleza", esto es, en las actividades esencialmente pacíficas del pensamiento y del trabajo, antes que en el uso de la violencia. Cf. SV, p. 23.

30 lbid., p. 15.

${ }^{31}$ Ibid.

${ }^{32} \mathrm{lbid}$.
} 
incurre en el error de presuponer que la política funciona al modo de una futurología de las acciones humanas y, tal como dice Arendt, “[...] sólo en un mundo donde nada de importancia sucediera, serían ciertas las predicciones de los futurólogos"33.

\section{§ 4. La noción arendtiana de poder}

La hipótesis política de que la acción violenta es aquella con la que se puede anticipar efectivamente a la trama inesperada e impredecible de los acciones humanas se ha visto reforzada, en nuestros tiempos, por la creencia moderna en un progreso de la historia y por la fe en que el conocimiento humano no solo tiene la capacidad de explicar el pasado sin romper con el continuum temporal, sino que, además, puede servir como guía para el futuro. Esto es lo que, en palabras de Arendt, descubrió Marx cuando invirtió el pensamiento de Hegel: "[...] cambió la dirección de la mirada del historiador, él podía mirar ahora confiadamente hacia el futuro"34. El Progreso, señala Arendt, "[...] ha proporcionado una respuesta a la inquietante pregunta ¿y qué haremos ahora?"35.

Esta respuesta, sin embargo, es una respuesta insatisfactoria, una respuesta que nos instala en una ignorancia acerca de la naturaleza misma de las acciones y de la labor de la política, que consiste precisamente en promover la aparición de dichas acciones, tal como había sido explicado en La condición humana. La violencia solo permite construir medios mediante los cuales se eleva la potencialidad humana de disuasión y aniquilamiento y, por lo tanto, de anulación de lo que la acción misma puede crear. Ese es su necesario -y único- fin; es una acción racional, única y exclusivamente, en tanto que es efectiva para alcanzar este fin $^{36}$. En ese sentido, se trata de un tipo de acción

\footnotetext{
${ }^{33} \mathrm{lbid}$.

${ }^{34}$ Ibid., p. 43.

$35 \mathrm{lbid}$.

${ }^{36}$ Señala Arendt al respecto que "[...] la violencia es racional sólo hasta el punto en que resulte efectiva para alcanzar el fin que deba justificarla" (ibid., p. 107). Cabe añadir que este fin, aun cuando tenga un sustento legal, solo puede ser un fin que sirve a corto plazo, pues "[...] las limitaciones de la ley nunca son por entero salvaguardas confiables contra la acción dentro del cuerpo político [...] la ilimitación de la acción no es más que la otra cara de su capacidad para
} 
humana justificable (en tanto que apela a un fin en el futuro para fundamentar su realización) pero que no es plausible a nivel político, pues la naturaleza de su fin atenta contra la naturaleza misma de las acciones. Esto, por una razón adicional: el fin de la acción violenta se encuentra siempre "[...] en peligro de verse superado por los medios a los que justifica y que son necesarios para alcanzarlo" ${ }^{37}$, es decir, el fin mismo de las acciones violentas tiene el paradójico destino de poder ser superado siempre por el desarrollo de los medios mediante los cuales dicho fin se lleva a cabo. No se trata de una paradoja cualquiera de las acciones humanas: con esta, se ha posibilitado la anulación de toda acción humana. La prueba más fehaciente de ello es que su perpetuación en la política ha permitido ver al aniquilamiento de toda la especie humana como una posibilidad latente; un objetivo político absurdo, pero viable, ante el desarrollo tecnológico de las armas de destrucción masiva.

Parece ser obvio, así, que Arendt retoma y amplía en Sobre la violencia una tesis que ya había sido anunciada en Los orígenes del totalitarismo. La perpetración de la violencia en la política atenta abiertamente contra la espontaneidad de la acción humana. Esta formulación se hace posible mediante la distinción entre violencia y poder. Mientras que el primer término responde a la necesidad humana de anular la espontaneidad de las acciones de los seres humanos, el último refiere a la capacidad humana de actuar concertadamente, es decir, se trata de aquello que permite la creación espontánea de nuevas tramas de acontecimientos a través de las acciones ${ }^{38}$.

El poder, a diferencia de la violencia, tiene así un fin en el futuro que es imposible de ser formulado. El poder es, para Arendt, un fin en sí mismo que exige legitimidad, no justificación. La legitimidad es, a diferencia de la justificación, una

establecer relaciones; es decir, su específica productividad" (Arendt, Hannah, La condición humana, p. 214).

${ }^{37}$ SV, p. 10. También puede verse sobre este punto: García, Dora Elvira, "La violencia como condición o disolución de lo político: Hannah Arendt y Carl Schmitt”, en: Signos filosóficos, VI, No. II (2004), pp.73-96.

${ }^{38}$ La concertación como rasgo inherente de las acciones que se sostienen en la práctica de la política ha permitido a Jürgen Habermas pensar esta concepción política arendtiana como afín a una noción comunicativa del poder. Cf. Habermas, Jürgen, "El concepto de poder en Hannah Arendt”, en: Perfiles filosófico-políticos, Madrid: Taurus, 2000. También sobre ello: Di Pego, Anabella, "Poder, violencia y revolución en los escritos de Hannah Arendt", en: Argumentos, No. 19, pp. I0I-I22. 
apelación al pasado, al momento en el cual las personas se reúnen, dialogan y deciden actuar juntos ${ }^{39}$. La legitimidad del poder reside, en ese sentido, en su apelación a la condición de posibilidad misma del establecimiento y cohesión sostenida, mediante el discurso, de una comunidad política en la que las acciones manifiestan su carácter creativo, en la que se realiza su espontaneidad.

\section{§ 5. La violencia y su relación con el mal}

Parece haber habido consenso desde siempre en que la violencia no es sino la más flagrante manifestación de poder en los regímenes políticos ${ }^{40}$. Desde el primigenio concepto de isonomía griego, pasando por la teoría hobbesiana acerca del Estado, así como por el republicanismo antagonista que afirma a ultranza el poder irrestricto del pueblo en su propia determinación legislativa, ha sido un prejuicio común en política entender el poder como un asunto de dominio basado en el manejo calculado de las acciones violentas. La reformulación arendtiana de la noción del poder busca distanciarse de la idea de que el efectivo dominio del hombre sobre el hombre sea una cuestión de violencia, y busca ubicar el problema a nivel de la concertación y la opinión. Con ello, además, nos describe uno de los rasgos fundamentales de los regímenes totalitaristas, permitiéndonos así mostrar claramente la relación que la violencia ha tenido con el mal.

Tal como afirma en Los orígenes del totalitarismo, el mal radical aparece cuando el régimen político nazi logra destruir la naturaleza espontánea de la acción humana. Esto es posible en tanto se ha creado una organización social en la que "[...] la banalidad del homo homini lupus es consecuentemente realizada"4l. La pregunta acerca de la relación entre el mal y la violencia parece así estar fuertemente emparentada con una profundización en la distinción arendtiana entre poder y violencia. Arendt enfatizará que no basta con decir que poder y violencia no son la misma cosa, sino que hay que concebir que son opuestos ${ }^{42}$. Esto se debe a una razón fundamental: la violencia es incapaz de crear poder

\footnotetext{
${ }^{39}$ Cf. SV, pp. 7I-72.

${ }^{40}$ Cf. ibid., p. 48.

${ }^{41}$ OT, vol. 3, p. 592.

${ }^{42}$ Cf. SV, p. 77.
} 
político; más bien, ahí donde ha faltado el poder, es decir, la capacidad para sostener acciones humanas concertadas, es que ha entrado a jugar un papel decisivo la violencia, pues, aunque del cañón de un arma, piensa Arendt, pueda surgir efectiva obediencia entre los seres humanos, jamás se producirá poder $^{43}$.

Dicho esto, Arendt se afirmará contraria a la tesis hegeliana y marxiana de que, siendo la violencia y el poder opuestos, estos se puedan desarrollar en una lógica dialéctica de progreso. No es posible, bajo ningún punto de vista, que del uso de la violencia surja, ni siquiera a largo plazo, el poder. Esta tesis se asienta, según su opinión, en una creencia filosófica aún más antigua y profunda: aquella que afirma que el mal es un modo privativo del bien, que, en suma, el mal es derivable del bien ${ }^{44}$. En el ensayo que nos ocupa, nuestra autora termina por plantearnos así que la violencia, si bien no es en sí misma algo equiparable con el mal, sí puede ser pensada como un modo de manifestación del mal que no debe entenderse como el momento previo de un bien superior, una suerte de mal "necesario" en tanto que es el momento previo de un bien por venir. Por el contrario, Arendt parece indicarnos que el uso deliberado de la violencia podría traer consigo un orden político en el que se instale esta forma del mal; en efecto, dada la racionalidad instrumental de la violencia, si con ella no se logra conseguir sus objetivos inmediatos, rápidamente se puede llegar a introducirla en todo el cuerpo político ${ }^{45}$. Esto, para Arendt, no sería un progreso en absoluto, sino la mera ampliación inevitable del uso de la violencia: "[dado que] la acción es irreversible [...] siempre resultará improbable en caso de una derrota un retorno al status quo. La práctica de la violencia, como toda acción, cambia el mundo, pero el cambio más probable [es que] originará un mundo más violento" ${ }^{46}$.

¿Este mundo, que se ha tornado más violento, es el mundo descrito por Arendt en Los orígenes del totalitarismo, aquel en el que el mal radical aparece? Nuestra autora no responde directamente a esta pregunta, pero sí se encarga de señalar que el uso de la violencia es la práctica común de todos

${ }^{43}$ Cf. ibid., p. 73.

${ }^{44}$ Cf. ibid., p. 77.

${ }^{45}$ Cf. ibid., p. 109.

${ }^{46} \mathrm{lbid}$. 
los gobiernos -en especial los totalitarios- para reemplazar su eventual falta de poder sobre los individuos ${ }^{47}$. Siendo el totalitaritarismo, por definición, un régimen político que aspira a la dominación total, su instrumentalización de la violencia, en reemplazo de su falta de poder absoluto, resulta ser una clave fundamental para comprender su eficacia en la anulación de la espontaneidad de las acciones humanas y, por lo tanto, una pieza clave en la comprensión del advenimiento del mal radical. 